Ensino, Saúde e Ambiente-V10 (3), pp.127-143, Dez. 2017

\title{
“COMBATENDO OS NEMATELMINTOS PARASITAS”: JOGO DIDÁTICO PARA FACILITAR A APRENDIZAGEM
}

\section{COMBATING THE NEMATELMINTOS PARASITES: DIDACTIC GAME TO FACILITATE THE LEARNING}

\author{
Junielson Soares da Silva ${ }^{1}$; Lúcia da Silva Fontes ${ }^{2}$ \\ ${ }^{1}$ Instituto Nacional de Pesquisas da Amazônia/ Programa de Pós-Graduação em Genética, Conservação e \\ Biologia Evolutiva/ Manaus-AM/ junielsonbio10@gmail.com \\ ${ }^{2}$ Universidade Federal do Piauí/ Programa de Pós-Graduação em Agronomia/ Campus Teresina-PI/ \\ lsfontes@ufpi.edu.br
}

\section{RESUMO}

Introdução: No Brasil, as doenças parasitárias são um problema de saúde pública, afetando principalmente aqueles que não possuem saneamento básico, cujos indivíduos com até 14 anos de idade são os mais afetados. Desse modo, faz-se necessário desenvolver nas crianças e adolescentes hábitos de higiene para a prevenção dessas doenças. Os jogos educativos no ensino de biologia são uma ferramenta que proporciona aprendizado dinâmico e significativo. Objetivo: avaliar a importância do jogo didático "Combatendo os nematelmintos parasitas" como agente facilitador da aprendizagem do conteúdo de nematelmintos parasitas. Método: confeccionou o jogo de tabuleiro, com perguntas, respostas e desafios, e em seguida foi aplicado em três turmas de $2^{\circ}$ ano do ensino médio de uma escola pública da cidade de Teresina-PI. Resultados e discussão: os resultados mostraram uma melhora no aprendizado dos alunos, já que a média de acertos do total de questões, passou de $48 \%$ no questionário pré-teste para $81 \%$ no pós-teste. Conclusão: desse modo, conclui-se que o jogo "Combatendo os nematelmintos parasitas", além de despertar nos alunos curiosidade pelo tema e empolgação pela metodologia, proporcionou melhora no aprendizado dos mesmos, mostrando-se uma eficiente ferramenta para o ensino de nematelmintos.

Palavras-chave: Ensino. Jogo lúdico. Nematelmintos. Verminoses. Aprendizagem.

\begin{abstract}
Introduction: In Brazil, the parasitic worm infections are a public health concern, mainly affecting those who do not have access to basic sanitation and children with up to 14 years old. In this way, it is necessary to develop, since childhood, good hygiene habits to prevent worm infections. The use of edutainment games is a tool to help in a dynamic and meaningful way the learning of biology. Aim: Evaluate the importance of the edutainment game "Fighting Parasitic Nematodes" as a facilitator of learning the parasitic nematodes content. Methods: A board game was developed, containing questions, answers and challenges, and then the game was applied in three classes of the secondary year of high school, in a public school at Teresina city, Piauí, Brazil. Results and discussion: Our results showed an improvement in the learning capacity of the students, since the average of correct answers went from $48 \%$ in the pre-test questionnaire to $81 \%$ in the post-test questionnaire. Conclusion: We concluded that the board game "Fighting Parasitic Nematodes" provided an improvement in the learning capacity, curiosity about the taught subject and excitement about the used methodology, proving to be an effective tool to support the teaching of nematodes.
\end{abstract}

Keywords: Education. Edutainment game. Nematodes. Learning. Worm infection. 
Ensino, Saúde e Ambiente-V10 (3), pp. $127-143$, De z. 2017

\section{INTRODUÇÃO}

Algumas espécies de nematelmintos são parasitas do homem e causam-lhes doenças (NEVES, 2009) como a ascaridíase, ancilostomíase ou amarelão, bichogeográfico, filaríose ou elefantíase e oxiurose (AMABIS; MARTHO, 2010; LINHARES; GEWANDSNAJDER, 2010).

Estima-se que todos os anos, cerca de 2 bilhões de pessoas são afetadas por algum organismo parasita em todo o mundo, principalmente em regiões pobres, onde as condições de saneamento básico e higiene são precárias, cuja ingestão da água e alimentos contaminados com ovos do parasita são a principal forma de contração das parasitoses intestinais (HICKMAN et al., 2004). O quadro clínico de cada verminose varia de acordo com o parasita, que pode levar à grave desnutrição, e até a morte caso não seja tratada (FERREIRA et al., 2006; AMABIS; MARTHO, 2010).

No Brasil, as doenças causadas por protozoários, platelmintos e nematelmintos parasitas são um problema de saúde pública, pois afetam grande parte da população, comprometendo o desenvolvimento físico $\mathrm{e}$ intelectual da pessoa afetada, principalmente aqueles em fase escolar. O Ascaris lumbricoides, conhecido como lombriga é o nematelminto parasita mais comum, principalmente crianças com até 14 anos de idade (ANDRADE et al., 2011; CONCEIÇÃO; SANTOS; NASCIMENTO, 2012; MELLO et al., 2013; ORO et al., 2013).

Considerando que os indivíduos em idade escolar são os mais afetados, é de fundamental importância que professores de Ciências e Biologia deem maior atenção ao ensino de doenças parasitárias, para desenvolver nos alunos hábitos de higiene, que previnam essas enfermidades (MELLO et al., 1988; SILVA; DANTAS, 2014). Sendo a educação em saúde, cujo objetivo é a divulgar a saúde por meio de práticas de ensino, capaz de gerar conhecimento sobre formas de prevenção a essas doenças (SALCI et al., 2013).

O ensino de Biologia deve tornar o aluno capaz de elaborar conceitos, eliminar conclusões errôneas e construir seu próprio conhecimento, mas em muitos casos, essa disciplina é considerada "chata" devido ao grande número de novos conceitos a serem compreendidos (KRASILCHIK, 2004). E embora alguns deles abstratos, poucos professores fazem correlação entre teoria e prática durante as aulas, o que dificulta ainda mais o aprendizado e torna cada vez menos interessante aprender (FERNANDES, 1998; TAVARES, 2013). Essa realidade não é diferente quando se trata do ensino de 
parasitologia, sendo que os jogos didáticos podem exercer perfeitamente a função de auxiliar no ensino de educação em saúde, pois estimulam a participação dos alunos, gerando aprendizado (SILVA; LEDA, 2012; SANTOS et.al, 2016).

O jogo didático possui aspecto lúdico e conteúdo educativo, capaz de gerar ou melhorar o aprendizado do sujeito (CUNHA, 1988), como já descrito por diversos estudos (FERNANDES, 1998; CAMPOS; FELÍCIO; BETOLOTO, 2002; KRASILCHICK, 2005; FREITAS, 2007), além de melhorar o desenvolvimento cognitivo e emocional do aluno (VYGOTSKY, 1991).

Os jogos didáticos são de fácil aquisição e baixo custo para o professor da educação básica (CAMPOS et al., 2002), possuem boa aceitação e quando aliados ao ensino proporcionam situações de brincadeira e/ou jogo, desenvolvendo no aluno a capacidade de resolver problemas (GRANDO, 2000). Outro caráter importante, é que eles complementam o ensino transmitido pelo professor e permitem ao educando construir seu próprio conhecimento (MIRANDA, 2001; CAMPOS; FELÍ́CIO; BETOLOTO, 2002).

Campos, Felício e Betoloto (2002) acreditam que o lúdico no ensino permite aos indivíduos participarem mutuamente, deixa as aulas mais dinâmicas e foge dos métodos tradicionais de ensino, tornando o aprendizado prazeroso e satisfatório. Os jogos didáticos estimulam o interesse do aluno e desenvolve níveis diferentes de experiência pessoal e social, ajudando-o a fazer novas descobertas (ZANON et al., 2008), garante aprendizado de forma descontraída, interativa e divertida, sem obrigação externa imposta (CAMPOS et al. 2002; CAMPOS; FELÍCIO; BETOLOTO, 2002; GALLEGO, 2007). O uso desse método de ensino tem ganhado espaço para complementar as aulas de Ciências e Biologia, já que podem ser confeccionados na forma de cartas e jogos de marcar (TOSCANI et al., 2007), painel (ALMEIDA et al., 2012), na forma de tabuleiro (MARQUES; SALOMÃO, 2014; SILVA; DANTAS, 2014) e de baralho (FERNANDES et al., 2014; SILVA et al., 2014).

Desse modo, o conteúdo de nematelmintos foi escolhido para ser trabalhado neste estudo, devido à sua importância e ao papel parasitológico que algumas espécies exercem, tendo em vista a ausência na literatura de jogos didáticos que trate exclusivamente dos indivíduos desse grupo, embora o conhecimento relacionado às doenças parasitárias provocadas por esses indivíduos seja de grande importância para a sociedade, especialmente para os sujeitos em formação, de modo que o jogo didático venha facilitar o aprendizado do aluno sobre as parasitoses. 
Desse modo, o presente estudo teve como objetivo, confeccionar e avaliar a importância do jogo didático "Combatendo os nematelmintos parasitas", como agente facilitador da aprendizagem do conteúdo de nematelmintos parasitas.

\section{MATERIAL E MÉTODOS}

O jogo foi elaborado baseado em modelos já descritos na literatura (BARBOSA et al., 2012; SILVA; DANTAS, 2014; SILVA et al., 2014) e no conteúdo de nematelmintos de livros didáticos, como Amabis e Martho (2010) e Linhares e Gewandsnajder (2010). Utilizou-se os programas Power Point e Word, para elaboração das peças do jogo, que depois foram impressas em papel A4, coladas em papel cartão e plastificadas para tornar o material mais resistente e duradouro.

Foram preparados 5 kits do jogo didático, cada um constituído por um manual de instruções, cinco pinos, um dado, 75 cartas perguntas (cor branca); 15 cartas de atitudes positivas (cor verde); 15 cartas de atitudes negativas (cor azul) e cédulas, como mostra a figura 1.

Figura 1: Peças do jogo: manual de regras (A); tabuleiro (B); cartas perguntas, de atitudes positivas e negativas (C); pinos (D); dado (E) e cédulas (F).
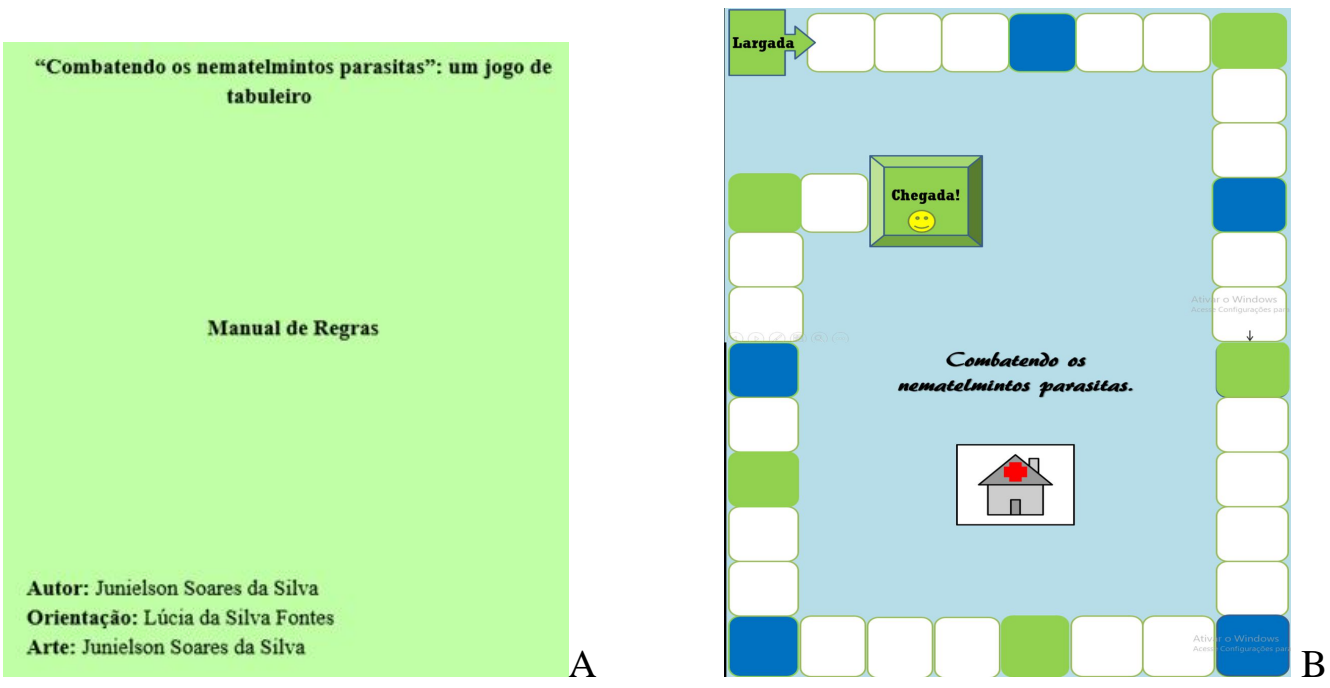

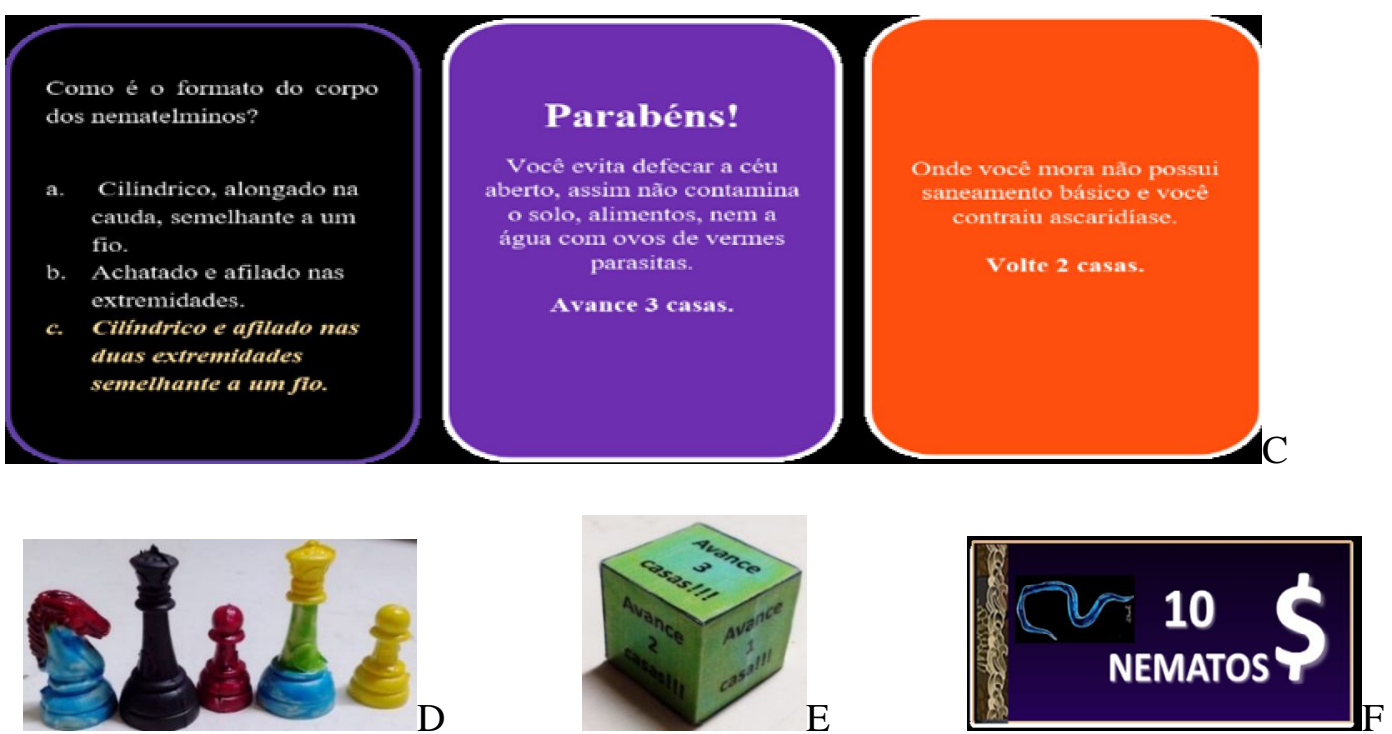

Fonte: Dados da Pesquisa.

\section{Regras do jogo}

Antes de iniciar o jogo, as cartas são embaralhadas e os pinos que representam cada jogador posicionados na casa "largada". É importante que os alunos tenham um livro de Biologia que pode ser utilizado para consultas durante o jogo.

A dupla que inicia o jogo, lança o dado que determina quantas casas irá avançar. Outro jogador retira uma carta pergunta e lê em voz alta para o jogador, que tem de um a dois minutos para responder. Caso acerte, deve avançar na trilha às casas indicadas no dado e aguardar a vez dos demais jogadores. Ao cair em uma casa de cor verde, que representa atitudes-positivas, retira e ler a carta, que dá direito a avançar casas. O mesmo acontece ao cair em casas de cor azul que representam atitudesnegativas, mas que contém punição, fazendo-a retroceder. Caso erre a resposta o jogador permanece no lugar e a carta será colocada de volta no baralho e embaralhada. O jogo continua nessa dinâmica até que uma dupla atinja a casa "chegada", sendo a vencedora.

\section{Aplicação do jogo}

O presente trabalho foi desenvolvido no Centro Estadual de Educação Profissional em Saúde "Monsenhor José Luís Barbosa Cortez", conhecido como Premen Sul, bairro Monte Castelo em Teresina, Piauí. Na escola ocorre 
concomitantemente ensino médio regular com cursos técnicos profissionalizantes da área de saúde.

Antes da atividade didática, foram realizados os procedimentos legais para pesquisa com seres humanos, informando e esclarecendo o objetivo da pesquisa e assinado um Termo de Consentimento Esclarecido. Depois o jogo didático "Combatendo os nematelmintos parasitas", foi aplicado para um total de 62 alunos de três turmas do $2^{\circ}$ ano do Ensino Médio.

$\mathrm{Na}$ primeira fase da atividade didática, foi explicado por meio de aula expositiva o conteúdo sobre nematelmintos, destacando suas principais características, e as doenças por eles causadas, enfatizando o modo de contração, sintomas, prevenção e tratamento, reservando um tempo para tirar as dúvidas dos alunos.

Na segunda fase, após a turma ser dividida em cinco equipes, foi apresentado o jogo e suas regras, descritas no tópico anterior. Em seguida cada equipe recebeu um kit do jogo e foram autorizados a iniciar a partida, que foi acompanhada por três monitores para dar suporte aos alunos em caso de dúvidas e garantir que as regras do jogo fossem seguidas pelos discentes, bem como manter a organização dos grupos.

\section{Avaliação da eficácia do jogo}

Em cada turma durante a exposição do conteúdo foi observado o conhecimento prévio, a curiosidade e interesse dos alunos quanto ao assunto abordado e para verificar a eficácia do jogo, este foi aplicado para os discentes, os quais foram submetidos a um questionário pré-teste (antes da aplicação do jogo), com sete perguntas de múltipla escolha sobre o tema abordado, como mostra o Quadro 1, e um pós-teste (após aplicação do jogo), com as mesmas sete perguntas do pré-teste, acrescido de quatro perguntas que visavam entender na opinião dos alunos se o jogo auxiliou no processo de aprendizagem e se haviam achado a atividade interessante.

\section{Quadro 1: Perguntas do questionário pré-teste e pós-teste, aplicados aos alunos do $2^{\circ}$ ano do}

\section{Premen-sul.}

1. O que são nematelmintos?

a) São vermes do corpo alongado e fino.

b) Vermes do corpo achatado dorsoventralmente.

c) Vermes do corpo cilíndrico, afilado nas extremidades, assemelhando-se a um fio.

d) Vermes do corpo cilíndrico, dividindo em anéis segmentados que auxiliam na locomoção.

2. Qual alternativa contém só organismos do filo dos nematelmintos.

a) Minhoca e lombriga

b) Lombriga e filária

c) Tênia e filária

d) Planária e ancilostoma 
3. Maneira pela qual uma pessoa contrai a ascaridíase?

a) Comer carne malcozida com formas imaturas do parasita.

b) Pela ingestão de água e alimentos contaminados com ovos do parasita.

c) Ser picado pela fêmea do mosquito Culex infestada com larvas do parasita.

d) Ter contato direto com terra contendo larvas do parasita.

4. Maneira pela qual uma pessoa contrai filaríose?

a) Comer carne malcozida com formas imaturas do parasita.

b) Ingerir ovos do parasita.

c) Ser picado pela fêmea do mosquito Culex infestada com larvas do parasita.

d) Ter contato direto com terra contendo larvas do parasita.

5. Maneira pela qual uma pessoa contrai ancilostomose?

a) Comer carne malcozida com formas imaturas do parasita.

b) Ingerir ovos do parasita.

c) Ser picado pela fêmea do mosquito Culex infestada com larvas do parasita.

d) Ter contato direto com o solo contaminado com larvas do parasita.

6. Das medidas a seguir, qual delas é eficaz para prevenir verminoses causadas por nematelmintos?

a) Comer carne de porco ou boi bem cozida e inspecionada.

b) Lavar bem mãos e verduras antes das refeições, filtrar ou ferver a água.

c) Andar descalço, pois larvas de nematelmintos não penetram nos pés.

d) Colocar telas nas janelas para evitar a entrada do mosquito Aedes.

7. Jeca Tatu é um homem da roça, lugar onde normalmente não há saneamento básico, nem tratamento da água a ser ingerida. O que facilita a contaminação de doenças verminoses e outras parasitoses humanas. Jeca Tatu apresentava coloração muito amarelada o que caracteriza anemia, apresentava indisposição e desanimo por tudo.

A história acima trata-se de um personagem criado Monteiro Lobato para descrever o quadro de sintomas de uma doença.

Qual é essa doença e o verme causador.

a. Ancilostomose- Ancylostoma duodenale

b. Ascaridíase- Ascaris lumbricoides

c. Elefantíase- Wunchereria bancrofti

d. Oxiurose- Oxyuro vermiculares

e. Esquistossomose- Schistosoma mansoni

Fonte: Dados da Pesquisa.

Os questionários pré-teste e pós-teste foram analisados e comparados quanto ao número de acertos para verificar se houve melhora no aprendizado após o jogo, e os gráficos foram plotados no software Excel® 2016.

\section{RESULTADOS E DISCUSSÃO}

Nesta atividade, assim como Castro e Costa (2011), foi verificado durante a aula expositiva que os alunos possuíam pouco conhecimento prévio do assunto, mas manifestaram interesse pelo tema, pois fizeram diversos questionamentos acerca do conteúdo abordado. Além disso, mostraram-se entusiasmados pela atividade, pois se tratava de uma metodologia nova, diferente das convencionais aulas ministradas pelo professor da disciplina. 
Comparando os dados de ambos os questionários (pré-teste e pós-teste), verificou-se um aumento no número de acertos após a aplicação do jogo, como mostra na figura 01 .

Ao questionar o que são nematelmintos, obteve-se $90 \%$ de acertos, tanto no pré-teste como no pós-teste, para a alternativa que dizia: são vermes do corpo cilíndrico, afilado nas extremidades, assemelhando-se a um fio, esses dados mostram que o conceito de nematelmintos foi bem compreendido com a aula expositiva.

$\mathrm{Na}$ pergunta, qual alternativa contém somente indivíduos do grupo dos nematelmintos, onde a correta era lombriga e filária, apenas $36 \%$ de participantes foram capazes de identificar a alternativa correta no pré-teste, mas após a aplicação do jogo, o número de acertos aumentou para 69\%. Mesmo assim, o número de acertos nessa pergunta continuou inferior às demais, mostrando que os alunos tiveram dificuldades de assimilar os nomes de todos os indivíduos do grupo nematelmintos, levando-os a confundir com platelmintos e até com anelídeos.

Quando questionados sobre a forma de contração da ascaridíase, no pré-teste $57 \%$ dos alunos acreditaram corretamente que a contração dessa doença se dá pela ingestão de água e alimentos contaminados com ovos do parasita, aumentando para 90\% o número acertos no pós-teste. Na pergunta sobre a maneira pela qual uma pessoa contrai filaríose, $54 \%$ dos participantes marcaram a reposta correta no pré-teste, que dizia que a contração se dá pela picada da fêmea do mosquito do gênero Culex, infestada com larvas do parasita, os acertos aumentaram para $88 \%$ no pós-teste.

Em relação ao modo de contração da ancilostomose, no pré-teste $59 \%$ dos participantes compreenderam que é por meio do contato direto com o solo contaminado com larvas do parasita, com a aplicação do jogo elevou o número de acertos para $91 \%$. Na pergunta, qual medida é eficaz na prevenção de verminoses, como as causadas por nematelmintos, para $66 \%$ dos participantes a prevenção dessas enfermidades se dá ao lavar bem mãos e verduras antes das refeições e filtrar ou ferver a água, e no pós-teste 97\% compreenderam que essas medidas de higiene ajudam a prevenir as parasitoses provocadas por indivíduos desse grupo.

Ao perguntar qual doença e verme causador apresentava Jeca Tatu, homem da roça, local sem saneamento básico. No pré-teste, $44 \%$ dos alunos marcaram a afirmativa correta, que dizia que a doença é a ancilostomose ou amarelão e o verme causador é o Ancylostoma duodenale, acertos que aumentaram para 73\% após o jogo. 
Figura 1: Porcentagem de acertos em cada pergunta, antes (pré-teste) e depois (pós-teste) da aplicação do jogo "Combatendo os nematelmintos parasitas" dos alunos do $2^{\circ}$ ano do ensino médio da Escola Premen-sul em Teresina-PI.

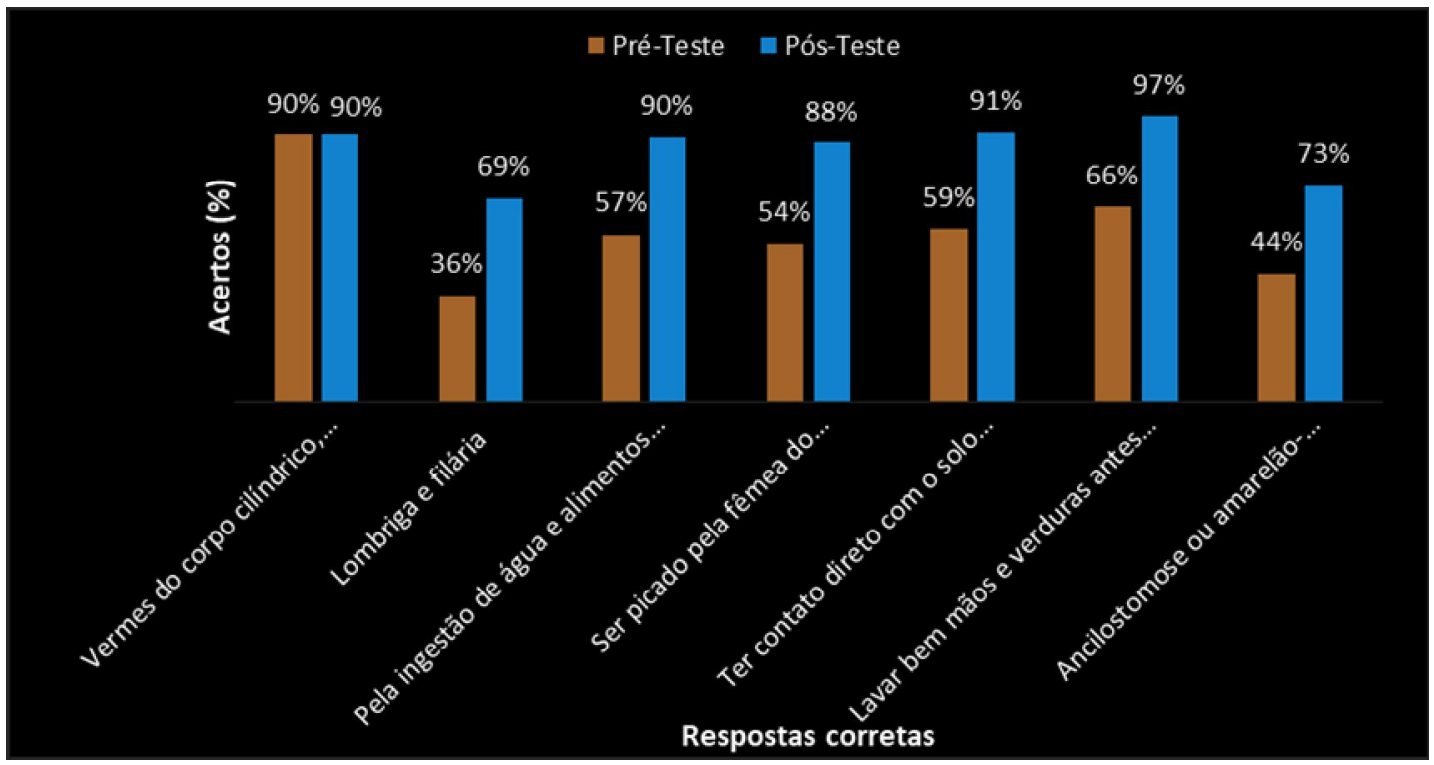

Fonte: Dados da Pesquisa.

Desse modo, comparando os acertos do questionário pré-teste com os do pósteste, verifica-se que houve aumento significativo no número de alunos que assimilaram corretamente a resposta das perguntas, obtendo-se, média de $81 \%$ no pós-teste, contra $48 \%$ no pré-teste (Tabela 01). Esses resultados mostram similaridade com os de Castro e Costa (2011), que obtiveram médias de 38,2\% e 92,8\% antes e depois de aplicarem o jogo “Super Átomo". Isso comprova que quando utilizados como método de ensino, os jogos educativos possibilitam aos alunos uma aprendizagem significativa.

Tabela 01: Análise comparativa de acertos nos questionários pré e pós-teste.

\begin{tabular}{|c|c|c|c|}
\hline \multirow[b]{2}{*}{ Questão } & \multirow[b]{2}{*}{ Alternativa correta } & \multicolumn{2}{|c|}{$\%$ acertos } \\
\hline & & Pré-teste & Pós-teste \\
\hline O que são nematelmintos? & $\begin{array}{l}\text { Vermes do corpo cilíndrico, } \\
\text { afilado nas extremidades, } \\
\text { assemelhando-se a um fio. }\end{array}$ & $90 \%$ & $90 \%$ \\
\hline $\begin{array}{l}\text { Qual alternativa contém só organismos do } \\
\text { filo dos nematelmintos? }\end{array}$ & Lombriga e filária & $36 \%$ & $69 \%$ \\
\hline $\begin{array}{l}\text { Maneira pela qual uma pessoa contrai a } \\
\text { ascaridíase? }\end{array}$ & $\begin{array}{l}\text { Pela ingestão de água e } \\
\text { alimentos contaminados com } \\
\text { ovos do parasita. }\end{array}$ & $57 \%$ & $90 \%$ \\
\hline $\begin{array}{l}\text { Maneira pela qual uma pessoa contrai } \\
\text { filaríose? }\end{array}$ & $\begin{array}{l}\text { Ser picado pela fêmea do } \\
\text { mosquito Culex infestada com } \\
\text { larvas do parasita. }\end{array}$ & $54 \%$ & $88 \%$ \\
\hline
\end{tabular}


Maneira pela qual uma pessoa contrai ancilostomose?

Das medidas a seguir, qual delas é eficaz para prevenir verminoses causadas por nematelmintos?

Jeca Tatu, homem da roça, lugar onde não há saneamento básico é um personagem criado por Monteiro Lobato para descrever o quadro de sintomas de uma doença. Ele tinha coloração amarelada, caracterizando anemia, além de indisposição e desanimo por tudo. Qual é essa doença e o verme causador?

Média de acertos
Ter contato direto com o solo contaminado com larvas do parasita.

Lavar bem mãos e verduras antes das refeições, filtrar ou ferver a água.

Ancilostomose ou amarelão- $\quad 44 \% \quad 73 \%$ Ancylostoma duodenale
$59 \% \quad 91 \%$

$66 \% \quad 97 \%$

\section{Fonte: Dados da Pesquisa.}

Constatamos que o uso de jogos educativos no ensino, tem um papel importante no aprendizado, como já observado por diversos autores (AMORIM et al., 2009; NASCIMENTO et al., 2013; SILVA; SILVA; SALES, 2016; SANTANA et al., 2016). Foi verificado que o jogo "Combatendo os nematelmintos parasitas" possibilitou melhora no aprendizado dos participantes, assim como foi notado por Barreto et al. (2013), após aplicar para alunos da $6^{\mathrm{a}}$ série do ensino fundamental um jogo didático na forma de tabuleiro sobre "verminose", abordando conteúdos de platelmintos e nematelmintos. Isso comprova o fato de Piaget (1978) considerar os jogos como ferramentas educacionais que possuem a função de fixar, e ou melhorar a fixação dos conteúdos em estudo.

O jogo didático em questão, ajudou os alunos a compreenderem a forma de contração, sintomas, tratamento e prevenção de doenças parasitárias causadas por nematelmintos, cujo conhecimento é de grande importância, pois ajuda formar cidadãos conscientes dos principais problemas de saúde pública enfrentados, especialmente pela população mais pobre e menos favorecida.

Nesse sentido, verificamos que o jogo "Combatendo os nematelmintos e verminoses" foi capaz de gerar conhecimento nos alunos, corroborando com os resultados obtidos por Santos et al. (2016), que constataram que o uso de metodologias alternativas gera bons resultados. Isso é importante, pois um dos objetivos da educação é possibilitar aos educandos e futuros cidadãos a capacidade de aprendizagem (POZO, 2003).

Ainda considerando a importância desse método de ensino, verificamos que o jogo, além de facilitar o aprendizado dos alunos, pode favorecer a pesquisa, a leitura e 
proporcionar uma aprendizagem com diversão e interatividade, assim como comprovado por Santana et al. (2016). Silva e Leda (2012) notaram um acréscimo significativo no conhecimento dos alunos que participaram do jogo sobre hábitos de saúde para prevenção de parasitoses intestinais. Assim como Silva e Dantas (2014), que consideram os jogos educativos uma ferramenta capaz de auxiliar na criação de hábitos de higiene, o jogo "Combatendo os nematelmintos parasitas", proporcionou aos estudantes o conhecimento de hábitos saudáveis, que possam prevenir doenças parasitárias, o que pode ser conferido ao questioná-los sobre medidas de prevenção às verminoses causadas por nematelmintos.

A similaridade dos dados encontrados nesse trabalho com os já descritos na literatura, reforça que a utilização de jogos lúdicos no ensino, motiva a participação e interação entre os indivíduos, deixando o ensino mais atraente e interessante para os alunos, que tornam-se autores do próprio aprendizado.

Sobre o que os alunos acharam do jogo didático, $79 \%$ dos participantes acharam o jogo ótimo, $19 \%$ acharam bom, apenas $2 \%$ acharam ruim e nenhum achou péssimo (Figura 2), os resultados à essa pergunta se assemelham aos obtido por Santana et al. (2016) que obteve 100\% de aprovação ao aplicar o jogo Mundo dos Parasitos.

Figura 2: Opinião dos alunos sobre o jogo educativo “Combatendo os nematelmintos parasitas".

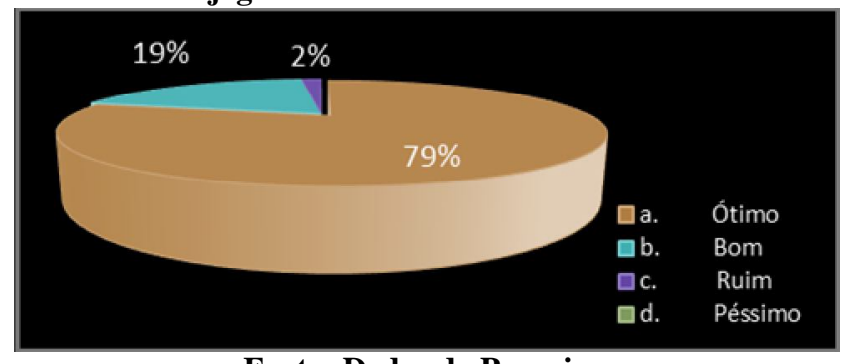

Fonte: Dados da Pesquisa.

Ao pedir para os alunos atribuírem uma nota de 6 a 10 ao jogo, $61 \%$ atribuíram nota 10,31\% atribuíram nota 9 e $8 \%$ deles atribuíram nota de 6 a 8 (Figura 3), demonstrando que o jogo teve boa aceitação pela maioria. Trindade et al. (2014) também verificou grande aceitação ao aplicar um jogo na forma de tabuleiro, sobre parasitoses. Assim como esses autores, nós acreditamos que os jogos didáticos possibilitam um aprendizado lúdico e prazeroso, atraindo a atenção dos alunos, mostrando que esse tipo de material didático pode auxiliar na aprendizagem, não só de conteúdos de parasitologia, mas de qualquer outro conteúdo de Biologia. 
Figura 3: Nota atribuída ao jogo didático, que variou de 06 a 10.

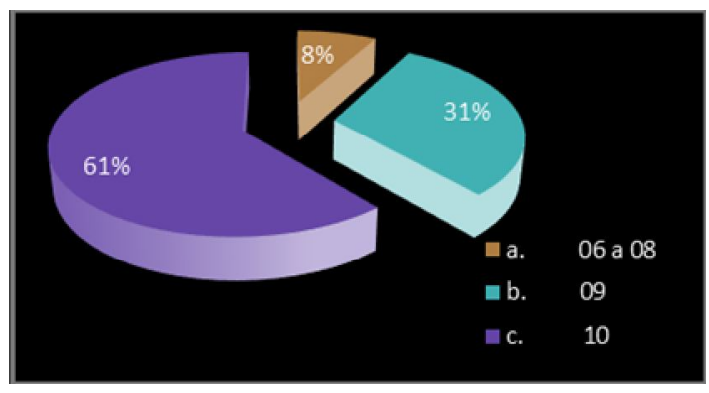

Fonte: Dados da Pesquisa.

Ao questiona-los se o jogo havia ajudado a compreenderem melhor o conteúdo de nematelmintos, $100 \%$ responderam sim e nenhum respondeu não, mostrando que os alunos manifestaram grande entusiasmo pela atividade, pois se tratava de uma metodologia nova, diferente das tradicionais aulas expositivas ministrada pelo professor de biologia, despertando o interesse e possibilitando aprendizado, como constatado por Castro e Costa (2011).

Em outra pergunta, questionou aos alunos sobre a importância da utilização de recursos de ensino, como o jogo "Combatendo os nematelmintos parasitas" para as aulas de Biologia, e assim como Legey et al. (2012) e Santana et al. (2016), 100\% dos participantes desta atividade consideram importante o uso de jogos no ensino de Ciências e/ou Biologia. A aceitação dos jogos pelos alunos pode ser explicada pelo caráter divertido que eles atribuem à forma de aprender (PINTO et al., 2015), uma vez que são eficazes na construção de um aprendizado de forma divertida, dinâmica e atraente (FIALHO, 2008).

Sendo assim, os jogos didáticos são uma importante estratégia para ensinar conteúdos abstratos e complexos, pois possibilitam o raciocínio, argumentação, interação entre os alunos, e entre estes e professores (CAMPOS; FELÍCIO; BETOLOTO, 2002). Durante a aplicação dos jogos, os alunos se inter-relacionam, discutem a teoria, relacionando o conhecimento adquirido com os objetivos dos jogos, sendo capazes de responder às perguntas (BARRETO et al., 2013).

Assim como Nascimento et al. (2013), foi verificado maior motivação dos estudantes, o que tornou a aula mais dinâmica e agradável, resultando em maior eficácia da aprendizagem. Como se esperava, o jogo didático proporcionou aos alunos uma competição saudável e garantiu um aprendizado significativo, reforçando a importância atribuída por Miranda (2001) do uso do lúdico no processo de ensino-aprendizagem. Para ele, os jogos têm vários objetivos a serem atingidos, relacionados à cognição 
(desenvolvimento da inteligência e da personalidade, fundamentais para a construção de conhecimentos); afeição (desenvolvimento da sensibilidade e da estima e atuação no sentido de estreitar laços de amizade e afetividade); socialização (simulação de vida em grupo); motivação (envolvimento da ação, do desafio e mobilização da curiosidade) e criatividade.

Desse modo, embora pouco usado no dia-a-dia da sala de aula, os jogos didáticos quando inseridos na lista de recursos didáticos, tem grande importância para o aprendizado, sem contar que esse material pode ser adaptado para vários conteúdos e utilizado em todas as etapas do ensino, devendo apenas adequar o nível de dificuldade à série.

\section{CONSIDERAÇÕES FINAIS}

Considerando os resultados obtidos, conclui-se que o jogo didático "Combatendo os nematelmintos parasitas" teve um importante papel no processo de ensino aprendizagem dos alunos sobre os nematelmintos parasitas, pois despertou nos participantes interesse pelo assunto, proporcionou motivação, participação e interação entre eles, além de possibilitar melhora no aprendizado sobre características dos nematelmintos, bem como das doenças causadas por eles.

Esse jogo pode ser utilizado tanto em sala de aula para reforçar o aprendizado, como também fora dela, ajudando na criação de hábitos de higiene pessoal, possibilitando ampliar o conhecimento acerca de doenças causadas por nematelmintos parasitas.

Embora encontre-se na literatura diversos jogos sobre parasitoses, mas nenhum deles abordam especificamente o assunto "nematelmintos". Sendo assim, o jogo aqui apresentado se constitui mais uma ferramenta de ensino para esse conteúdo, e irá contribuir com alunos e professores, possibilitando um aprendizado significativo. No entanto faz-se necessário maior utilização destes recursos por professores, que comprovadamente melhora os índices de aprendizado, mas que ainda são pouco utilizados. 


\section{REFERÊNCIAS BIBLIOGRÁFICAS}

ALMEIDA, R. A.; PEQUENO, G. A.; AMORIM, F. D.; AMADOR, D. D.;

MARINHO, A. H.; ROSALMEIDA, M. D. P.; FARIAS, L. X. N.; CARVALHO, L. L. F.; SOUSA, J. O.; NOGUEIRA, R. B. S. S.; LIMA, C. M. B. L.; ALENCAR, V. M. P. D. Jogo Parasitológico: uma estratégia no ensino-aprendizagem da parasitologia. Rede de Cuidados em Saúde, v. 6, n. 1, p. 1-15, 2012.

AMABIS, J. M.; MARTHO, G. R. Biologia: biologia dos organismos. Vol.2. São Paulo; Moderna. 2010.

AMORIM, F. D. B.; AMADOR, D. D.; MARINHO, A. H.; ALMEIDA, R. A.; ROSALMEIDA, M. D. P.; FARIAS, L. X. N.; CARVALHO, L. L. F.; SOUSA, J. O.; NOGUEIRA, R. B. S. S.; LIMA, C. M. B. L.; ALENCAR, V. M. P. D. Aprender e Ensinar Parasitologia Brincando. In: XI Encontro de Iniciação à Docência, UFPBPGR, João Pessoa, 2008. Disponível em:

http://www.prac.ufpb.br/anais/xenex_xienid/xi_enid/monitoriapet/ANAIS/Area6/6CCS DFPMT03-P.pdf. Acessado em outubro de 2016.

ANDRADE, E. C.; LEITE, I. C. G.; VIEIRA, M. T.; ABRAMO, C.; TIBIRIÇÁ, S. H. C.; SILVA, P. L. Prevalência de parasitoses intestinais em comunidade quilombola no Município de Bias Fortes, Estado de Minas Gerais, Brasil, 2008. Epidemiol. Serv. Saúde, v. 20, n. 3, p. 337-344, 2011.

BARBOSA, J. L.; DANTAS, S. M. M. M.; FREITAS, J, SILVA T. N.; PARANHOS, J. D. N. "Aprendendo Mitose e Meiose de forma simples". Revista Sbenbio. Goiânia-GO. n. $4,2012$.

BARRETO, L. M.; GAVA, M.; FERRARINI, T. D.; SANTOS, C. M.; FERREIRA, C. D.; CARMASSI, A. Jogo didático como auxílio para o ensino de zoologia de invertebrados. In Resumos do I CONICBIO / II CONABIO / VI SIMCBIO, v.2, p.1 -14. Recife, PE, 2012. Disponível em: http://www.unicap.br/simcbio/wpcontent/uploads/2014/09/JOGO-DID\%C3\%81TICO-COMO-AUX\%C3\%8DLIOPARA-O-ENSINO-DE-ZOOLOGIA-DE-INVERTEBRADOS.pdf. Acesso em outubro 2016.

CAMPOS, L. M. L.; FELÍCIO, A. K. C.; BORTOLOTO, T. M. A produção de jogos didáticos para o ensino de Ciências e Biologia: uma proposta para favorecer a aprendizagem. Cadernos dos Núcleos de Ensino, p. 35-48. São Paulo, 2002.

CASTRO, B. J.; COSTA, P. C. F. Contribuições de um jogo didático para o processo de ensino e aprendizagem de Química no Ensino Fundamental segundo o contexto da Aprendizagem Significativa. Revista electrónica de investigación en educación en ciências, v. 6, n. $2,1-13,2011$.

CONCEIÇÃO, L. C. A.; SANTOS, T. S.; NASCIMENTO, L. M. Proposta de atividade lúdica para o ensino das parasitoses destinada ao $2^{\circ}$ ano do Ensino Médio. In VI Colóquio Internacional "Educação e Contemporaneidade”, p. 1-9, São Cristóvão, SE, Brasil, 2012. Disponível em: http://educonse.com.br/2012/eixo 06/PDF/62.pdf. Acesso em outubro 2016. 
CUNHA, N. Brinquedo, desafio e descoberta. Rio de Janeiro: FAE, 1988.

FERNANDES, H. L. Um naturalista na sala de aula. Ciência \& Ensino, v. 5, 1998.

FERNANDES, S. M. A.; MAVIGNIER, R. D.; SILVA, R. D. S.; SILVA, F. D. R.; DANTAS, S. M. M. M. Baralho Didático: Temas de Biologia para Ensino Médio. Revista SBEnBio, v. 7, p. 6974-6983, 2014.

FERREIRA, H.; LALA, E.R. P.; MONTEIRO, M. C.; RAIMONDO, M. L. Estudo epidemiológico localizado da frequência e fatores de risco para enteroparasitose e sua correlação com o estado nutricional de crianças em idade pré-escolar. Publ. UEPG: Ciências Biológicas, v. 12, n. 4, p. 33-40, 2006.

FIALHO, N. N. Os Jogos Pedagógicos como Ferramentas de Ensino. In VIII Congresso Nacional de Educação da PUCPR - EDUCERE, p. 12298 - 12306, Curitiba, Paraná, 2008. Disponível em:

http://www.pucpr.br/eventos/educere/educere2008/anais/pdf/293_114.pdf. Acesso em outubro de 2016.

FREITAS, O. Equipamentos e materiais didáticos. Brasília-DF; Universidade de Brasília UnB. 2007.

GALLEGO, A, J. P. A utilização dos jogos como recurso didático no ensinoaprendizagem da Matemática. Trabalho de Conclusão do Curso (Curso de Pedagogia). Universidade Estadual Paulista, São Paulo, Brasil, 2007.

GRANDO, R. C. O jogo na educação: aspectos didático-metodológicos do jogo na educação matemática. Unicamp, Campinas, São Paulo, 2001.

HICKMAN, J. C.; CLEVELAND, P.; ROBERTS, L. S.; LARSON. A. Princípios integrados de zoologia. Rio de Janeiro: Guanabara Koogan, 2004.

KRASILCHIK, M. Prática de Ensino de Biologia. São Paulo: Editora da USP, 2005.

LEGEY, A. P.; MOL, A. C. A.; BARBOSA, J. V.; COUTINHO, C. M. L. M. Desenvolvimento de Jogos Educativos Como Ferramenta Didática: um olhar voltado à formação de futuros docentes de ciências. Revista de Educação em Ciência e Tecnologi $a$, v. 5, n. 3, p.49- 82, 2012.

LINHARES, S.; GEWANDSZNAJDER, F. Biologia Hoje. São Paulo: Ática, 2010.

MARQUES, F. S.; SALOMÃO, S. R. Ensino de Biologia e atividades lúdicas: o jogo de tabuleiro conectando conteúdos de evolução e ecologia no Ensino Médio. Revista de Ensino de Biologia da Associação Brasileira de Ensino de Biologia. Revista SBEnBio, v. 7, p. 2073-, n. 2014.

MELLO, D. A.; PRIPAS, S.; FUCCI, M.; SANTORO, M. C.; PEDRAZZANI, E. S. Helmintoses intestinais: I - Conhecimentos, atitudes e percepção da população. Revista de Saúde Pública, v. 22, n. 2, p. 140-149, 1988. 
MELLO, F. C. S.; PILAR, B. C.; STROHER, D. J.; MANFREDINI, V. Prevalência de Parasitoses em Escolares da Escola Estadual de Ensino Fundamental Paso de los Libres no Município de Uruguaiana, RS. NewsLab, 2013.

MIRANDA, S. No fascínio do jogo, a alegria de aprender. Ciência Hoje, v. 28, n. 168, p. 64-66, 2001.

NASCIMENTO, A. M. D.; LUCCA JUNIOR, W.; SANTOS, R. L. C.; DOLABELLA, S. S. Parasitologia Lúdica: O jogo como agente facilitador na aprendizagem das parasitoses. Scientia Plena, v. 9, n. 7, p. 1- 6, 2013.

NEVES, D. P.Parasitologia Dinâmica. SãoPaulo: Atheneu, 2009.

ORO, D.; KOPROSKI, G.; ORO, N. A.; SBARDELOTTO, C.; SEGER, J. Prevalência de parasitas intestinais em crianças de Descanso, Santa Catarina, Brasil. Unoesc \& Ciência, v. 1, n. 2, p. 151-155, 2011.

PIAGET, J. O nascimento da inteligência na criança. Rio de Janeiro: Zahar, 1978.

PINTO, L. C. M; MELO, M. J. C.; LOPES, L. K. C.; SOUZA, J. R. T. A importância dos jogos didáticos para o ensino de ciências no nível fundamental. In $\mathbf{1 4}^{\mathbf{o}}$ Encontro de Profissionais de Química da Amazônia - PA, p. 199-206, Pará, 2015.

POZO, J. I. Aprendizagem de conteúdos e desenvolvimento de capacidades no ensino médio. In COLL, C. Psicologia da aprendizagem no Ensino Médio. Rio de Janeiro: Editora, 2003.

SALCI, M. A.; MACENO, P.; ROZZA, S. G.; SILVA, D. M. G. V.; BOEHS, A. E.; HEIDEMANN, I. T. S. B. Educação em saúde e suas perspectivas teóricas: algumas reflexões. Texto \& Contexto - Enfermagem, v. 22, n. 1, p. 224-230, 2013.

SANTANA, R. S.; OLIVEIRA, L. T. S.; LIMA, R. A.; DUARTE, E. C.; MAYWORM, M. A. S. Jogos didáticos e o ensino por investigação: contribuições do jogo mundo dos parasitos. Revista Internacional de Formação de Professores (RIFP), v. 1, n. 4, p. 80-97, 2016.

SANTOS, M. C.; COSTA, I. G.; TEXEIRA, Q. D.; COSTA, F. J.; NICÁCIO, L. M. F. Ensino de parasitologia com crianças do ensino fundamental: utilização de modelos didáticos com massinha. Fasem Ciências, v. 9, n. 1, p. 5-15, 2016.

SILVA, J. S.; DANTAS, S. M. M. M. "Conhecendo as parasitoses do brasil": jogo de tabuleiro. Revista SBEnBio, v. 7, p. 4328 - 4338, 2014.

SILVA, T. V.; LEDA, L. R. Intervenções educativas sobre parasitoses intestinais: aplicação de um jogo para alunos do ensino fundamental. Saúde \& Amb. Rev., v. 7, n. 2, p. 23-07, 2012.

SILVA, T. R.; SILVA, J. A.; SALES, L. A. O jogo didático como facilitador da aprendizagem em parasitologia e sua contribuição na formação do docente em ciências 
biológicas. In Anais do XIV Congresso Internacional de Tecnologia na Educação, p. 10. Recife, PE, Brasil. 2016. Disponível em:

http://demo.cubo9.com.br/senac/pdf/poster/045.pdf. Acesso em fevereiro de 2017.

SILVA, J. S.; SOUSA, F. S.; SANTOS, F. C.; DANTAS, S. M. M. M. "Baralho dos animais invertebrados": aprendendo de forma dinâmica. Revista SBEnBio, v. 7, p. 4319 4327, 2014.

TAVARES, P. C. Utilização de jogo educativo como proposta para favorecer o ensino de ciências nas turmas do $8^{\circ}$ ano da Escola Municipal Maria Caproni de Oliveira, município de Carvalhópolis MG. Monografia (Curso de Biologia), Instituto Federal de Educação, Ciência e Tecnologia do Sul de Minas Gerais, Machado, Minas Gerais, Brasil, 2013.

TOSCANI, N. V.; SANTOS, A. J. D. S. Desenvolvimento e análise de jogo educativo para crianças visando à prevenção de doenças parasitológicas. Interface -

Comunicação, Saúde, Educação, v. 11, n. 22, p. 281-294, 2007.

TRINDADE, F. F.; DANTAS, M. A. T.; DONATO, C. R.; VIEIRA, F. S. Descobrindo as parasitoses: jogo educativo para o ensino de ciências. Educationis, v. 2, n. 1, p. $26 \square 34,2014$.

VYGOTSKY, L. S. A formação social da mente: o desenvolvimento dos processos psicológicos superiores. São Paulo: Martins Fontes, 1991.

ZANON, D. A. V.; GUERREIRO, M. A. S.; OLIVEIRA, R. C. Jogo didático Ludo Químico para o ensino de nomenclatura dos compostos orgânicos: projeto, produção, aplicação e avaliação. Ciências \& Cognição, v. 13 n. 1, p. 72-81, 2008. 